\title{
High-Dose Methylprednisolone Reduces Cytokine-Induced Adhesion Molecules on Human Brain Endothelium
}

\author{
Maurizio Gelati, Elena Corsini, Anna Dufour, Giorgio Massa, Sergio Giombini, \\ Carlo L.Solero, Andrea Salmaggi
}

\begin{abstract}
Objective: We investigated the in vitro effects of low- and high-dose methylprednisolone (MP) on the cytokine-induced expression of HLA-DR, ICAM-1 and VCAM-1 on human brain microvessel endothelial cells (HBMECs). Methods: Brain endothelium was obtained from microvessels included in the apparently normal white matter of surgical specimens of nine patients. Cells were stained with monoclonal antibodies anti-HLA-DR, anti-ICAM-1 and anti-VCAM-1 and analysed by flow cytometry as fluorescence histograms. The mean fluorescence intensity (MFI) of HBMECs treated with different stimuli was calculated. Results: $\gamma$-IFN-induced HLA-DR was down-regulated in a dosedependent manner by MP. High-dose MP reduced the TNF- $\alpha$-induced ICAM-1 and VCAM-1 expression. Conclusions: The down-regulation of adhesion molecules on cerebral endothelial cells could decrease mononuclear cell transmigration through the blood brain barrier and consequently the perivascular infiltrates. The results add support to the rationale for high-dose MP treatment in multiple sclerosis relapses.
\end{abstract}

\begin{abstract}
RÉSUMÉ: Des doses élevées de méthylprednisolone réduisent l'expression des molécules d'adhésion induites par les cytokines sur l'endothélium de cerveaux humains. Objectif: Nous avons évalué les effets de faibles et de fortes doses de méthylprednisolone (MP) in vitro sur l'expression de HLA-DR, ICAM-1 et VCAM-1, induite par des cytokines, sur les cellules endothéliales de microvaisseaux de cerveaux humains (CEMCHs). Méthodes: De l'endothélium de cerveau a été obtenu de microvaisseaux provenant de substance blanche apparemment normale contenue dans des spécimens chirurgicaux provenant de huit patients. Les cellules ont été marquées au moyens d'anticorps monoclonaux anti-HLA-DR, anti-ICAM-1 et anti-VCAM-1 et analysées par cytométrie de flux sous forme d'histogramme de fluorescence. La moyenne d'intensité de la fluorescence des CEMCHs traitées au moyen de différents stimuli a été calculée. Résultats: Le HLA-DR induit par $\gamma$-IFN était régulé à la baisse de façon dose dépendante par la MP. De fortes doses de MP diminuaient l'expression de ICAM-1 et VCAM-1 induite par TNF- $\alpha$. Conclusions: La régulation à la baisse des molécules d'adhésion sur les cellules endothéliales cérébrales pourrait diminuer la transmigration des cellules mononucléaires à travers la barrière hémato-encéphalique et conséquemment les infiltrats périvasculaires. Ces résultats appuient le concept d'administrer de fortes doses de MP dans le traitement de poussées de sclérose en plaques.
\end{abstract}

Can. J. Neurol. Sci. 2000; 27: 241-244

Clinical trials have suggested the efficacy of high-dose methylprednisolone (MP) in the treatment of multiple sclerosis (MS) relapses, ${ }^{1}$ while low-dose MP is not as effective and might lead to relapse reactivation in some cases. ${ }^{2}$ Immunological studies focusing on the effects of steroids treatment in MS produced interesting data regarding the interface lymphomonocytes-brain endothelium.

Particularly, a reduced adhesion of lymphomonocytes to human umbilical vein endothelial cells was obtained after three hours from a single infusion of high-dose of MP $(1 \mathrm{~g})$ in clinically active patients. ${ }^{3}$ Also, some authors report a transient downregulation of adhesion molecules on peripheral blood mono- nuclear cells after treatment of MS relapses with i.v. administration of $\mathrm{MP}{ }^{4}$ while other authors have shown that steroids are able to down-regulate the expression of some adhesion molecules on human umbilical vein endothelial cells. ${ }^{5}$ The reduced expression of these molecules, after steroid

From the Istituto Nazionale Neurologico C.Besta, Milano, Italy.

RECEIVED JANUARY 24, 2000. ACCEPTED IN FINAL FORM APRIL 25, 2000. Reprint requests to: A. Salmaggi, Istituto Nazionale Neurologico C.Besta, Via Celoria 11, 20133 Milano, Italy. 
administration in vivo, could actually decrease the transmigration of mononuclear cells through the brain microvessels and/or the presentation of (auto)antigen at the blood brain barrier. The adhesion/transmigration process involves a number of molecular interactions, ${ }^{6,7}$ among which ICAM-1/LFA-1 and VCAM1/VLA-4 have been shown to be relevant in experimental allergic encephalomyelitis. ${ }^{8,9}$ Interestingly, it has been suggested that Class II molecules could also be involved in lymphocyte adhesion to murine brain endothelium. ${ }^{10}$

The aim of this study was to explore if steroid treatment may target the expression of adhesion molecules on human brain microvessel endothelial cells (HBMECs). We investigated the in vitro effects of both low-dose MP and high-dose MP treatment on the cytokine-induced expression of HLA-DR, ICAM-1 and VCAM-1 on HBMECs.

\section{MATERIALS AND METHODS}

HBMECs were obtained from microvessels included in the apparently normal white matter of surgical specimens of nine patients $(6 \mathrm{~F}, 3 \mathrm{M}$, age range $26-76$, mean age 48.6), four of them operated for meningiomas, four operated for low-grade gliomas and one for pituitary adenoma.

After removal of leptomeninges and vessels from the surgical specimen, HBMECs were isolated by trypsinization, filtration through a 100 mesh screen and centrifugation in $15 \%$ dextran. The cells were then incubated in collagenase and plated on collagen-coated dishes. For the experiments, HBMECs were grown on 48 multiwell plates and used at the second passage. In our hands, HBMECs after the 4th passage display changes in surface amounts of ICAM-1 and VCAM-1, and also of their inducibility by cytokines (unpublished observations). The endothelial cells' morphology and HLA-DR, ICAM-1 and VCAM-1 expression in basal conditions were suggestive of normal cerebral microvessel endothelial cells, as described in the literature. ${ }^{11,12,13}$.

The culture purity ( $>95 \%$ ) was tested by a von Willebrand factor (VWF) antigen staining by indirect immunofluorescence (mouse anti-human VWF and goat anti-mouse FITC, Sigma).

Preliminary experiments were performed to evaluate the most effective stimulus in inducing HLA-DR, ICAM-1 and VCAM-1 expression on endothelium. We tested both $\gamma$-IFN and TNF- $\alpha$ and, while HLA-DR was induced only by $\gamma$-IFN treatment, ICAM-1 and VCAM-1 were only slightly increased by $\gamma$-IFN, with a more marked up-regulation after TNF- $\alpha$ incubation.

Grown cells were then studied in basal conditions and after 72 hours stimulation with the proinflammatory cytokines $\gamma$-IFN (250 U/ml) for HLA-DR induction and TNF- $\alpha$ (10 ng/ml) for ICAM-1 and VCAM-1 expression respectively.

In order to evaluate the most effective dose of MP in downregulating the expression of cytokine-induced adhesion molecules, we tested five different concentrations of the drug in preliminary experiments (i.e., 65, 150, 300, 450 and $650 \mu \mathrm{g} / \mathrm{ml}$ ).

All nine HBMECs samples were then stimulated with "highdose" (450 $\mu \mathrm{g} / \mathrm{ml}$, i.e., the lowest dose maintaining an optimal efficacy in the down regulation of adhesion molecules) and "low-dose" MP (65 $\mu \mathrm{g} / \mathrm{ml})$, alone or in combination with proinflammatory cytokines. HBMECs were ultimately stained with monoclonal antibodies (anti HLA-DR fluoresceinconjugated, Becton Dickinson, CA, anti ICAM-1 and anti VCAM-1 phycoerythrin-conjugated, Ancell Corporation, MN) and analysed by flow cytometry as fluorescence histograms. A monoclonal antibody for $\mathrm{IgG}_{1}$ and $\mathrm{IgG}_{2 \mathrm{a}}$ (Simutest Control, Becton Dickinson, CA) was used to evaluate nonspecific staining. The mean fluorescence intensity (MFI) of HBMECs treated with different stimuli was calculated.

Statistical analysis of the MFI of unstimulated, cytokinestimulated and high and low dose-MP-treated (with or without cytokine) HBMECs respectively was performed using the Wilcoxon signed rank test.

\section{RESULTS}

The results obtained are reported in the Table and Figures 1 and 2 .

HLA-DR was induced only after $\gamma$-IFN stimulation but not

Table: Mean fluorescence intensity fluctuations after cytokines and MP treatment

\begin{tabular}{|c|c|c|c|}
\hline & HLA-DR & ICAM-1 & VCAM-1 \\
\hline Basal & n.d. ${ }^{\bullet}$ & $129.8 \pm 34.4$ & n.d. \\
\hline$\gamma$-IFN $(250 \mathrm{U} / \mathrm{ml})$ & $509.8 \pm 109.4^{\mathrm{a}}$ & n.p. ${ }^{*}$ & n.p. \\
\hline${ }^{\wedge} \mathrm{MP}_{1}+\gamma-\mathrm{IFN}$ & $430.7 \pm 115.0^{\mathrm{b}}$ & n.p. & n.p. \\
\hline${ }^{\circ} \mathrm{MP}_{\mathrm{h}}+\gamma$-IFN & $240.3 \pm 87.9^{c}$ & n.p. & n.p. \\
\hline $\mathrm{MP}_{1}+\mathrm{TNF}-\alpha$ & n.p. & $1742.1 \pm 542.0$ & $205.8 \pm 41.0$ \\
\hline
\end{tabular}

\begin{tabular}{lc}
\hline not detectable & ${ }^{\wedge} \mathrm{MP}_{1}$ : low-dose MP \\
${ }^{*}$ not performed & ${ }^{\circ} \mathrm{MP}_{\mathrm{h}}$ : high-dose MP
\end{tabular}

Due to the minor effect of $\gamma$-IFN on ICAM-1 and VCAM-1 expression, observed in preliminary experiments, these data are omitted in the table.

Wilcoxon signed Rank Test: a-b $\mathrm{p}<0.015$; a-c $\mathrm{p}<0.008$; d-e $\mathrm{p}<0.015$; f-g $\mathrm{p}<0.011$

(Data obtained in nine individuals. In five of these, the experiments were run in duplicate, with no differences between the observed values. Only one value for each individual was retained in the statistical evaluation). 


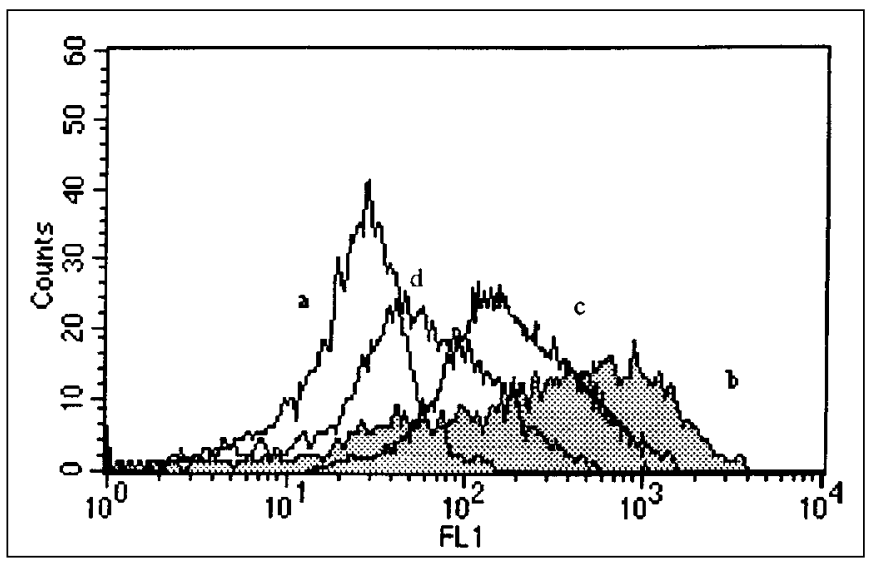

Figure 1a: Down-regulation of $\gamma$-IFN-induced HLA-DR by high-dose $M P$. The $x$ axis reports the fluorescence 1 values (FL1), while the y axis reports the number of cells. (a) Simutest Control-marked HBMECs (b) $\gamma$-IFN stimulated HBMECs (filled gray histogram) (c) $\gamma$-IFN+150 $\mu g / m L-M P$-stimulated HBMECs (d) $\gamma$-IFN+high-dose MP-stimulated HBMECS

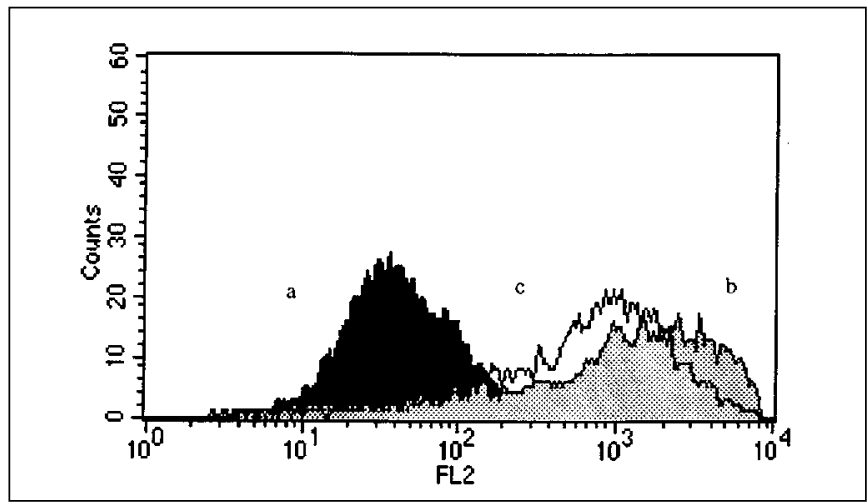

Figure 1b: Down-regulation of TNF- $\alpha$-induced ICAM-1 by high-dose $M P$. The $x$ axis reports the fluorescence 2 values (FL2), while the y axis reports the number of cells. (a) Basal ICAM-1 expression on HBMECs (filled black histogram) (b) TNF- $\alpha$-stimulated HBMECs (filled gray histogram) (c) TNF- $\alpha+$ high-dose MP-stimulated HBMECs

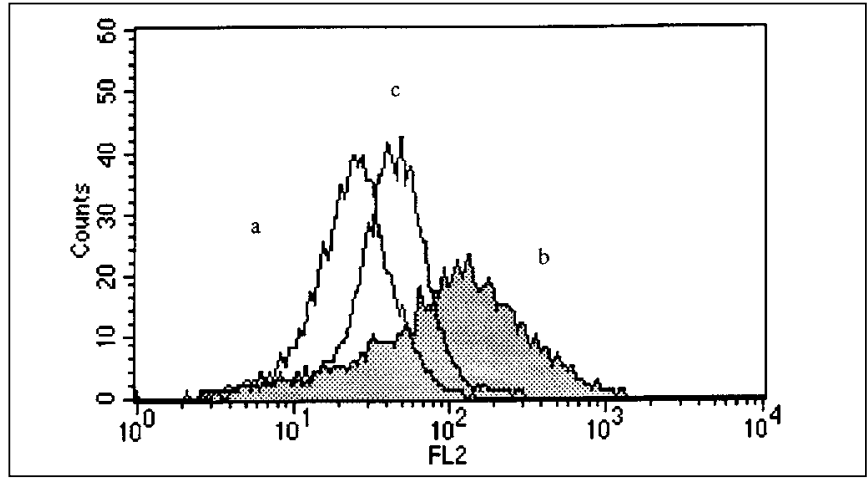

Figure 1c: Down-regulation of TNF- $\alpha$-induced VCAM-1 by high-dose $M P$. The $x$ axis reports the fluorescence 2 values (FL2), while the y axis reports the number of cells. (a) Simutest Control-marked HBMECs $(b)$ $T N F-\alpha$-stimulated HBMECs (filled gray histogram) (c) TNF- $\alpha+$ highdose MP-stimulated HBMECs after TNF- $\alpha$ stimulation; the induced expression was downregulated in a dose-dependent manner by MP (Figure 1a and Table).

ICAM-1 was expressed constitutively and increased after stimulation by TNF- $\alpha$ : high-dose MP reduced the induced expression significantly (Figure $1 \mathrm{~b}$ and the Table); the intermediate concentration of $300 \mu \mathrm{g} / \mathrm{ml}$ was as effective as the highest (data not shown). Low-dose MP was ineffective in counteracting TNF- $\alpha$-induced ICAM-1 expression (Table). Both high and low-dose MP alone did not modify the constitutive expression of ICAM-1 nor were able to induce expression of HLA-DR or VCAM-1 (unshown). VCAM-1 was not expressed in basal conditions (percentage of positive cells $<10 \%$ ), while it was induced only after stimulation with TNF- $\alpha$ : the TNF- $\alpha-$ induced expression was reduced significantly with high-dose MP (Figure 1c and the Table); the $300 \mu \mathrm{g} / \mathrm{ml}$ concentration was also able to decrease TNF- $\alpha$-induced VCAM-1 expression to a similar extent, whereas this was not the case for low-dose MP (Table).

\section{Discussion}

In comparison with our previous results ${ }^{14}$ on human umbilical vein endothelial cells (where only a minimal decrease in $\gamma$-IFNinduced HLA-DR was detected with high-dose MP), in the present report high-dose MP was indeed effective in reducing $\gamma$ IFN-induced expression on HBMECs: this might be due either to district-specific differences and/or to the different passages of endothelial cells. While the reduction in MFI observed in cytokine-induced HLA-DR and VCAM-1 expression after highdose MP incubation seems to be biologically relevant (the values are reduced to the half), the biological significance of ICAM-1 down-regulation is doubtful, since the MP-reduced values are still near to those induced by TNF- $\alpha$. Similar results have been found in an in vivo study in patients with rheumatoid arthritis, in which a pulse of $1 \mathrm{~g}$ of MP induced a marked decrease in Eselectin and a smaller reduction in ICAM-1 expression on synovial vascular endothelium. ${ }^{15}$ In this respect, it must be stressed that in vivo infusion of a single dose of $1500 \mathrm{mg}$ of MP,

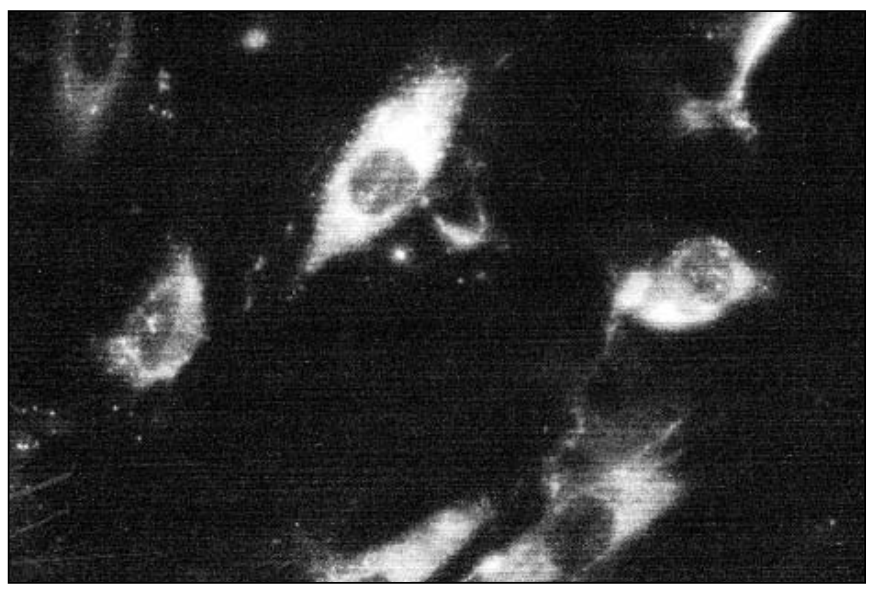

Figure 2: Human brain endothelial cell von Willebrand factor (VWF) antigen staining by indirect immunofluorescence (mouse anti-human VWF and goat anti-mouse FITC, Sigma). 
i.v., in MS patients, induced peak plasmatic concentration of the drug close to those used in our work. ${ }^{16}$

In conclusion, our data show that the immunomodulatory effects of steroids, already described on endothelium from other tissues $^{14,15,17}$ may target also HBMECs and this is actually complementary to the similar down-regulation induced on circulating immune cells, as mentioned above. ${ }^{4}$ The finding gets relevance particularly when put in synergistic combination with $\beta$-IFN treatment, which, in turn, is able to down-regulate $\gamma$-IFNinduced HLA-DR expression on the surface of HBMECs, ${ }^{18}$ as well as to reduce in vitro transendothelial migration of TNF- $\alpha-$ or $\gamma$-IFN-activated leukocytes. ${ }^{19}$

A recent study has actually shown that MP treatment during relapse in $\beta$-IFN-treated MS patients produces a persistent reduction of enhancement in MRI-evaluated lesions, suggesting that $\beta$-IFN could in some way prolong the beneficial effects of steroids on the blood brain barrier. ${ }^{20}$ This could be due to a downregulation of HLA-DR and adhesion molecules in combination with a decrease of MMP-9 production, observed both in $\beta$-IFN ${ }^{21}$ and in steroid treatment. ${ }^{22}$

Overall, the in vitro results obtained in this study add some rationale to treatment of MS relapses with high-dose MP; further studies are needed to better delineate possible interactions of MP with drugs such as $\beta$-IFN able to modulate long-term disease activity.

\section{REFERENCES}

1. Milligan M, Newcombe R, Compston DAS. A double-blind controlled trial of high-dose methylprednisolone in patients with multiple sclerosis. 1. Clinical effects. J Neurol Neurosurg Psychiatry 1987; 50: 511-516.

2. La Mantia L, Eoli M, Milanese C, et al. Double-blind trial of dexamethasone versus methylprednisolone in Multiple Sclerosis acute relapses. Eur Neurol 1994; 34: 199-203.

3. Gelati M, Corsini E, Dufour A, et al. Reduced adhesion of PBMNCs to endothelium in methylprednisolone-treated MS patients: preliminary results. Acta Neurol Scand 1997; 96: 283-292.

4. Droogan AG, Crockard AD, McMillan SA, et al. Effects of intravenous methylprednisolone therapy on leukocyte and soluble adhesion molecule expression in MS. Neurology 1998; 50: $224-230$

5. Aziz KE, Wakefield D. Modulation of endothelial cell expression of ICAM-1, E-selectin, and VCAM- 1 by $\beta$-estradiol, progesterone, and dexamethasone. Cell Immunol 1996; 167: 79-85.

6. Oppenheimer-Marks N, Davis LS, Tompkins-Bogue D, et al. Differential utilization of ICAM-1 and VCAM-1 during the adhesion and transendothelial migration of human Tlymphocytes. J Immunol 1991; 147: 2913-2923.

7. Baron JL, Madri JA, Ruddle NH, et al. Surface expression of $\alpha 4$ integrin by $\mathrm{CD} 4 \mathrm{~T}$ cells is required for their entry into brain parenchyma. J Exp Med 1993; 177: 57-68.
8. Archelos JJ, Jung S, Maurer M, et al. Inhibition of experimental autoimmune encephalomyelitis by an antibody to the intercellular adhesion molecule ICAM-1. Ann Neurol 1993; 34: 145-154.

9. Yednock TA, Cannon C, Fritz LC, et al. Prevention of experimental autoimmune encephalomyelitis by antibodies against $\alpha 4 \beta 1$ integrin. Nature 1992; 356: 63-66.

10. Goodal CA, Curtis ASG, Lang SC. Modulation of adhesion of lymphocytes to murine brain endothelial cells in vitro: relation to class II Major Histocompatibility Complex expression. J Neuroimmunol 1992; 37: 9-22.

11. Huynh HK, Dorovini-Zis K. Effects of interferon- $\gamma$ on primary cultures of human brain microvessel endothelial cells. Am J Pathol 1993; 142: 1265-1278.

12. Wong D, Dorovini-Zis K. Up-regulation of intercellular molecule adhesion-1 (ICAM-1) expression in primary cultures of human brain microvessel endothelial cells by cytokines and lipopolysaccharide. J Neuroimmunol 1992; 39: 11-22.

13. Wong D, Dorovini-Zis K. Expression of vascular cell adhesion-1 molecule-1 (VCAM-1) by human brain microvessel endothelial cells in primary cultures. Microvasc Res 1995; 49: 325-339.

14. Dufour A, Corsini E, Gelati M, et al. Modulation of ICAM-1, VCAM-1 and HLA-DR by cytokines and steroids on HUVECs and human brain endothelial cells. J Neurol Sci 1998; 157(2): 117-121.

15. Youssef PP, Triantafillou S, Parker A, et al. Effects of pulse methylprednisolone on cell adhesion molecules in the synovial membrane in rheumatoid arthritis. Reduced E-selectin and Intercellular Adhesion Molecule-1 expression. Arthritis Rheum 1996; 39(12): 1970-1979.

16. Defer GL, Barré J, Ledudal P, et al. Methylprednisolone infusion during acute exacerbation of MS: plasma and CSF concentrations. Eur Neurol 1995; 35: 143-148.

17. Cronstein BN, Kimmel SC, Levin RI, et al. A mechanism for the antiinflammatory effects of corticosteroids: the glucocorticoid receptor regulates leucocyte adhesion to endothelial cells and expression of endothelial-leucocyte adhesion molecule-1 and intercellular adhesion molecule-1. Proc Natl Acad Sci USA 1992; 89: 9991-9995.

18. Corsini E, Gelati M, Dufour A, et al. Effects of $\beta$-IFN-1b treatment in MS patients on adhesion between PBMNCs, HUVECs and MS -HBECs: an in vivo and in vitro study. J Neuroimmunol 1997; 79: 76-83.

19. Lou J, Gasche Y, Zheng L, et al. Interferon-beta inhibits activated leukocyte migration through human brain microvascular endothelial cell monolayer. Lab Invest 1999; 79 (8): 1015-1025.

20. Gasperini C, Pozzilli C, Bastianello S, et al. Effect of steroids on Gd-enhancing lesions before and during recombinant beta interferon 1a treatment in relapsing-remitting multiple sclerosis. Neurology 1998; 50(2): 403-406.

21. Corsini E, Gelati M, Dufour A, et al. Reduction of transendothelial migration of mononuclear cells in $\beta$-IFN $1 \mathrm{~b}$ treated MS patients. Ann Neurol 1999; 46(3): 435.

22. Rosenberg GA, Dencoff JE, Correa N, et al. Effect of steroids on CSF matrix metalloproteinases in multiple sclerosis: relation to bloodbrain barrier injury. Neurology 1996; 46: 1626-1632. 